\title{
ResearchOnline@JCU
}

This is the author-created version of the following work:

Thorley, Craig, Almond, Louise, Gregory, Adam, McAlonan, Vanessa, and McLoughlin, Amy (2018) An archival analysis of sexual assault victims' age estimation accuracy when describing stranger offenders. Psychology, Crime \& Law, 24 (10) pp. 1030-10449.

Access to this file is available from:

https://researchonline.jcu.edu.au/54682/

Please refer to the original source for the final version of this work: 
An archival analysis of sexual assault victims' age estimation accuracy when describing stranger offenders

Dr. Craig Thorley ${ }^{1}$, Dr. Louise Almond ${ }^{2}$, Adam Gregory ${ }^{3}$, Vanessa McAlonan², Amy McLoughlin ${ }^{2}$

${ }^{1}$ Department of Psychology, James Cook University, Australia ${ }^{2}$ School of Psychology, University of Liverpool, UK

${ }^{3}$ National Crime Agency, UK

Corresponding author:

Dr. Craig Thorley

Department of Psychology,

James Cook University,

Townsville, 4814,

Australia

Phone: +61 747816354

Email: craig.thorley@jcu.edu.au 


\begin{abstract}
Approximately $10 \%$ of all serious sexual assaults in England and Wales involve victims and offenders who are strangers. The victims often estimate the stranger offender's age during police interviews. These age estimations, if accurate, can help identify offenders. This archival analysis examined the accuracy of 546 stranger sexual assault victims' age estimations. It also examined whether their accuracy can be predicted by victim age offender age differences, victim age - offender estimated age differences, victim race offender race differences, victim intoxication, victims' duration of exposure to offenders, the time delay between assaults and age estimations, whether offenders have weapons, and whether offenders use sighting precautions. Amongst the descriptive findings, we found victims' mean age estimation error was 4.78 years, the degree of over- and underestimation was equivalent, that only $12.5 \%$ of age estimations were within 0.99 years of an offender's true age, but $90 \%$ were within 9.99 years of an offender's true age. Only victim age offender age differences and, importantly, victim age - offender estimated age differences predicted age estimation accuracy: as age differences decreased, accuracy increased. These findings can help predict stranger sexual assault victims' age estimation accuracy in future cases.
\end{abstract}

Keywords: sexual assault, rape, age estimation, own-age bias, memory 


\section{An archival analysis of sexual assault victims' age estimation accuracy when describing stranger offenders}

Each year, approximately 97,000 adults in England and Wales are victims of serious sexual assaults, including rape and attempted rape (Office for National Statistics [ONS], 2013). In $10 \%$ of these cases, the victims are assaulted by a stranger (ONS, 2013). Nearly nine out of ten stranger sexual assault victims estimate the offender's age during police interviews (Thomas, Aitken, Lucy, \& Feist, 2004). If accurate, these age estimations can help identify the offenders. Here, we present findings from an archival analysis examining sexual assault victims' age estimation accuracy when describing stranger offenders. This was done by comparing the victims' age estimations during their initial police interviews to the convicted offenders' actual age at the time of the assault. Additionally, we examined whether eight offence-specific factors, such as victim age - offender age differences, can predict victims' age estimation accuracy.

\section{Overall age estimation accuracy}

Age estimation accuracy is typically studied in the laboratory, with participants studying photographs of strangers' faces and then guessing their ages. Participants can use several facial features to estimate adults' ages, such as their hair colour and volume, eyebrow thickness, skin elasticity, and earlobe size (see Rhodes, 2009; Moyse, 2014, for reviews). When adults' ages are estimated in these idealised conditions, they are often inaccurate by approximately 6 years (see Moyse, 2014) ${ }^{1}$. For example, Voelkle, Ebner, Lindenberger, and Riediger (2012) presented young adults with pictures of strangers, aged 19 to 80, and had them estimate their ages; their absolute age estimation error was 5.91 years. Several studies

\footnotetext{
${ }^{1}$ This value relates to studies where absolute age estimation error is calculated. Some studies have calculated average age estimation error only, so the calculations included negative values from underestimations and positive values from overestimations. These negative and positive values often cancelled each other out during the averaging, resulting in lower error rates than reported here (see Rhodes, 2009).
} 
have, however, examined overall estimation accuracy outside of the laboratory (e.g., Ebbesen \& Rienick, 1998; Tollestrup, Turtle, \& Yuille, 1994; van Koppen \& Lochun, 1997). The Tollestrup et al. (1994) study is perhaps most relevant here as it used archival analyses to examine 12 robbery victims' age estimation accuracy when describing their robbers. The victims' absolute age estimation error was 2.87 years, so nearly half that observed in laboratory studies.

The present study examines sexual assault victims' age estimation accuracy and, to date, only Thomas et al. (2004) have studied this issue. They conducted an archival analysis focussing on 372 rapes/attempted rapes with female victims/male offenders that were reported to police in the United Kingdom between 1998 and 2002. As their findings appeared in a limited-access government report, and we will be attempting to replicate several of them, the most relevant are described here. They found that only 66 of the victims provided an exact age estimation (in years) and only 8 of these (12\%) were accurate. Their absolute error was not calculated. Victims were more likely to provide age range estimations (e.g., 25 - 35 years of age). Unsurprisingly, narrower ranges were less likely to include the offender's true age. For example, $34 \%$ of estimations with a 1 - 2-year range, but $62 \%$ with a 6 - 10 -year range, included the offender's true age. Narrow age estimations that accurately include the offender's true age are, therefore, the exception rather than the rule.

\section{Offence-specific factors and age estimation accuracy}

Thomas et al. (2004) also examined whether several offence-specific factors influenced the sexual assault victims' age estimation accuracy. The impact of six of these on victims' age estimation accuracy, alongside two novel factors, will also be examined in this study. The six offence-specific factors examined in both studies are victim age - offender age differences, victim age - offender estimated age differences, victims' alcohol consumption levels prior to assaults, the duration victims were exposed to offenders, whether offenders 
had weapons that were seen by the victims, and whether offenders used any sighting precautions. The two novel factors examined here are victim race - offender race differences and the passage of time between assaults and victims providing age estimations. Previous findings examining the impact of these factors on age estimation accuracy are now considered.

Victim age - offender age differences. In Thomas et al.'s (2004) report, the victims were aged 7 - 91 whereas the offenders were aged $13-59$. Nearly $60 \%$ of the victims were at least one year younger than their assailant and nearly $30 \%$ were more than 10 years younger. Importantly, Thomas et al. found age estimation accuracy increased as victim age - offender age differences decreased. This effect is known as an own-age bias. A similar own-age bias effect has been observed in laboratory-based age estimation studies (e.g., Anastasi \& Rhodes, 2006; Moyse \& Brédart, 2012; George \& Hole, 1995; George, Hole, \& Scaife, 2000; Voelkle et al., 2012). The leading explanation for this effect is the perceptual-expertise hypothesis, which suggests that individuals have most contact with members of their own age group and become experts at estimating own-age, relative to other-age, faces (George \& Hole, 1995; Harrison \& Hole, 2009; Moyse \& Brédart, 2012).

Victim age - offender estimated age differences. Whilst it is interesting to know that sexual assault victims' age estimation accuracy when describing stranger offenders is subject to an own-age bias, this knowledge has little practical value during police investigations. In stranger sexual assault cases, investigators do not know an offender's true age, so cannot use this knowledge to establish the likely accuracy of a victim's age estimation. Investigators therefore need to know the likely accuracy of a victim's age estimation when they only know the difference between the victim's age (e.g., 25 years old) and the victim's estimation of the offender's age (e.g., 29 years old). Thomas et al. (2004) are the only researchers to have examined this and they found the own-age bias effect generalised when an offender's age was 
estimated (and not known), meaning their age estimations were increasingly accurate as the difference between their age and their estimation of the stranger offender's age decreased.

Alcohol consumption. Examining whether alcohol consumption impacts upon sexual assault victims' age estimation accuracy is important as about half of all victims have consumed alcohol prior to their assault (e.g., Abbey, Zawacki, Buck, Clinton, \& McAuslan, 2004; Littleton \& Breitkopf, 2006; Orchowski, Untied, \& Gidycz, 2013). Thomas et al. are the only researchers to have examined this and they found alcohol consumption, by an unspecified number of victims, had no effect on age estimation accuracy. Their finding, however, must be treated with caution as alcohol consumption was a binary yes/no variable, meaning the volume consumed, and its impact upon age estimation accuracy, was not considered. High levels of intoxication during an event can impair recollection of it (Read, Yuille, \& Tollestrup, 1992; Thorley \& Christiansen, 2018; Van Oorsouw \& Merckelbach, 2012; Van Oorsouw, Merckelbach, \& Smeets, 2015), although the ability to remember faces is often unaffected (see Altman, Schreiber Compo, McQuiston, Hagsand \& Cervera, In Press). Whether or not high levels of intoxication can impair sexual assault victims' ability to recollect offenders' ages is unknown but warrants examination.

Duration of exposure. Thomas et al. (2004) also considered whether the (selfreported) amount of time a sexual assault victim spent with a stranger offender impacted upon their age estimation accuracy. The times ranged from one minute - 19 hours, with onethird of victims being exposed to the offender for less than 30 minutes and just over half (51\%) being exposed for less than an hour. Thomas et al. found the duration of exposure did not influence age estimation accuracy. Their analysis, however, only compared the age estimation accuracy rates of victims who were exposed to offenders for less than one hour to those of victims who were exposed to offenders for more than one hour. This meant that very different exposure times, such as one minute and 59 minutes, were treated equivalently. This 
overly broad categorisation may have resulted in a Type 2 Error. Indeed, other archival studies suggest that an eyewitness's duration of exposure to a stranger offender can influence their age estimation accuracy. For example, Granhag, Ask, Rebelius, Öhman, and Mac Giolla (2013) examined real eyewitness's descriptions of a murderer who was seen for less than 15 seconds. Only $8.3 \%$ of age estimations were accurate to within 2.5 years of the murderer's age. In contrast, Fahsing, Ask, and Granhag (2004) and Yuille and Cutshall (1986) examined real eyewitness's descriptions of armed robbers who were seen for considerably longer (e.g., 10 minutes for Yuille \& Cutshall, $1986^{2}$ ). The former found $38.10 \%$ were accurate to within 2.5 years of the offender's true age, whereas the latter found nearly $50 \%$ were accurate to within 2 years of the offender's true age (no exact figure is reported). It is likely that eyewitnesses who saw the offender for longer were better able to encode features that are useful for making accurate age estimations. It would therefore be helpful to know whether this duration of exposure effect, when duration is treated as a continuous variable, generalises to sexual assault victims' age estimation accuracy when describing stranger offenders.

Seeing a weapon. Thomas et al. (2004) reported that $25.32 \%$ of the offenders in their archival analysis had a weapon that was seen by their victim. In the only analysis of this issue to date, however, they found that seeing a weapon, compared to not seeing one, had no impact upon victims' age estimation accuracy.

Use of sighting precautions. Finally, Thomas et al. (2004) found 39\% of stranger offenders attempted to hide their faces, with the sighting precautions ranging from tying a blindfold around the victim's eyes (4\%), covering the victim's eyes with their hands or a garment (30\%), wearing a disguise (5\%), and telling the victims to look away (12\%). In the

\footnotetext{
${ }^{2}$ Fahsing et al. (2004) did not state how long participants were exposed to the offenders for in their studies, preventing direct comparisons between their work and that of Granhag et al. (2013). The same author (Granhag) wrote both articles and mentions that the exposure duration in the 2013 study "was considerably shorter than any of the cases examined by Fahsing et al. (2004)" (p.929).
} 
only analysis of this issue to date, they found that victims' age estimation accuracy did not differ according to the sighting precautions used.

Victim race - offender race differences. Thomas et al. (2004) reported that $93 \%$ of victims, but only $78 \%$ of offenders, in their analysis were White European. Evidence that racial differences may impact upon age estimation accuracy comes from a laboratory-based study by Dehon and Brédart (2001) where White participants (in a White majority country) were better at estimating the ages of White faces than Black faces. Dehon and Brédart suggest this own-race bias effect, similar to the own-age bias effect, occurs due to perceptualexpertise whereby individuals have most contact with members of their own race and become experts at estimating own-race, relative to other-race, faces. Interestingly, they also found Black participants were equally good at estimating the ages of Black and White faces. They argue this effect is also consistent with the perceptual-expertise hypotheses as their Black participants (who lived in a White majority country) would have had frequent contact with both Black and White people. Bearing these effects in mind, it would be helpful to know whether victim race - offender race differences predict sexual assault victims' age estimation accuracy when describing stranger offenders.

The passage of time. No studies have examined whether sexual assault victims' age estimation accuracy when describing stranger offenders is influenced by the passage of time. This is important to know as an archival analysis by Feist, Ashe, Lawrence, McPhee, and Wilson (2007) found less than half of rapes in England and Wales were reported to the police on the same day, with $14 \%$ reported more than six months later. In the closest approximation to this, Ebbesen and Rienick (1998) asked participants to estimate the age of a person who told them a story. Participants made two age estimations, with the initial age estimation taking place either immediately, after 1 day, or after 7 days, and the second estimation taking place after 28 days. Irrespective of when the age estimation was made, just over $50 \%$ of 
estimations were accurate to within two years of the story teller's true age. Yuille and Cutshall (1986) obtained similar null effects when they compared eyewitnesses' age estimation accuracy when describing an unfamiliar armed robber two days after the offence and four to five months after the offence. Thus, age estimation accuracy does not seem to change with time, even when a repeated recall attempt is inserted into the retention interval. If similar null effects occur when sexual assault victims estimate stranger offenders' ages, then this is helpful for police investigators to know.

\section{Aims and hypotheses}

This archival analysis examines sexual assault victims' age estimation accuracy when describing stranger offenders. It attempts to replicate and, importantly, extend Thomas et al.'s (2004) earlier findings in several ways, using a larger number of cases. Initial exploratory analysis will examine victims' absolute age estimation error. Confirmatory analyses will then examine age estimation accuracy when exact estimations (in years) are provided. Consistent with Thomas et al. (2004), it is expected that approximately one-tenth of these will be accurate. Most victims, however, provide age range estimations or non-specific verbal descriptions of an offender's age (e.g., he was in his late twenties). In these circumstances, investigators often use the middle value in the range, also known as a midpoint, as the age estimation. The accuracy of these midpoints has not previously been examined. As these midpoints are currently used to prioritise nominals (i.e., potential suspects), establishing their accuracy is critical. Exploratory analyses will therefore examine (1) overall midpoint age estimation accuracy, (2) whether exact age estimations and midpoint age estimations differ in accuracy, (3) whether each age estimation type has a bias towards under- or overestimating an offender's age, and (4) whether narrower or broader age range estimations, when reduced to midpoints, are associate with greater accuracy. 
Confirmatory and exploratory analyses will also examine whether age estimation accuracy can be predicted by the eight offence-specific factors discussed above. With regards to the former, Thomas et al.'s (2004) earlier research suggests that victim age - offender age differences and victim age - offender estimated age differences will predict age estimation accuracy, with an own-age bias being evident. Exploratory analyses will examine if victim race - offender race differences can predict age estimation accuracy. Dehon and Brédart's (2001) laboratory study found age estimation accuracy can be subject to an own-race bias but that this effect may be mediated by the amount of other-race contact people have. In our analyses, sexual assault victims' other-race contact cannot be assessed, so firm predictions cannot be made regarding whether an own-race bias will be observed. As Thomas et al. (2004) found neither alcohol consumption prior to an assault, the duration of exposure to an offender, nor the presence of a weapon or use of sighting precautions during an assault influenced sexual assault victims' age estimation accuracy, null effects must be predicted here. As discussed, however, their overly-broad dichotomisation of the former two factors meant true effects may have been missed. Similar dichotomisations will be avoided here. Finally, confirmatory analyses will examine whether the passage of time between an assault and an age estimation can predict age estimation accuracy: consistent with past research by Ebbesen and Rienick (1998), null effects are expected.

\section{Method}

\section{Data}

The dataset was compiled by the National Crime Agency's (NCA) Serious Crime Analysis Section (SCAS) data analysts. It contained information about 688 solved sexual assault cases reported to the police between 2000 and 2013. In this research, solved cases are defined as those where an offender has been identified and convicted for the crime. All victims in the dataset were female and each was assaulted by a single male offender. All 
offences in the dataset were classed as either rape, attempted rape, or indecent or sexual assault. For brevity, all cases will be referred to as sexual assaults. The data was taken from the victims' initial police statements about the sexual assaults and police records showing the convicted offenders' demographic details. All the data coding described below was independently checked for accuracy by three of the authors prior to analyses.

\section{Data exclusions}

This study is interested in sexual assault victims' age estimation accuracy when describing stranger offenders, so all cases in the analyses needed to involve victims and offenders who had never previously met. In 72 cases, the victim was a prostitute and the offender was a client. We could not confirm that the victim and offender in these cases had never previously met, so they were excluded from all analyses. All cases also needed to contain information necessary for coding the dependent variable, which is age estimation accuracy. Six cases were excluded as the victim's estimation of the offender's age was missing. Sixty-four cases were also excluded as the victims only provided vague descriptions of the offender's age, making it impossible to derive age estimations. Examples of these vague descriptions include "Didn't appear old", "Older than 18 years", and "Young looking". Combined, these exclusions reduced the number of cases in the analyses from 688 to 546.

\section{Dependent variable}

The dependent variable was the victim's age estimation accuracy. It was calculated in one of two ways, depending on the specificity of the victim's age estimation.

In 120 cases (21.98\%), victims provided an exact age estimation (in years). In these cases, the offender's chronological age was subtracted from the victim's age estimation. For example, if the offender was 31 years of age but the victim estimated the offender to be 35 years of age, then the victim's age estimation accuracy score was -4 years. In all analyses, negative signs were ignored (e.g., -4 years was classed as 4 years). 
In the remaining 426 cases $(78.02 \%)$, the victims provided age range estimations (e.g., 20 - 30 years old) or non-specific verbal estimations (e.g., mid-twenties). When an age range was provided, the midpoint of that range was used as the age estimation (mirroring the practice of real police investigators and those who assist them). For example, if the victim estimated that the offender was 20 - 30 years old, a midpoint of 25 years old was used as the age estimation. In instances where a non-specific verbal estimation referred to an early, mid, or late period in a decade, the nearest interquartile point to that description was used as the age estimation. For example, if the victim said the offender was in his "early twenties", we interpreted this to mean he was between 20 and 25 and used 22.5 years of age as the midpoint estimation. In more complex cases where the victim said, for example, the offender was in his "late twenties to mid-thirties", we interpreted this to mean he was between 25 and 37.5 and used 31.25 years of age as the midpoint estimation. These midpoint estimations (e.g., 22.5 years old) were then subtracted from the offender's actual age (e.g., 23 years old) to create a single midpoint age estimation accuracy score (e.g., 0.50 years). Again, negative signs were ignored in all analyses.

\section{Factors}

\section{Victim age - offender age differences and victim age - offender estimated age}

differences. The victims ranged from 8 - 94 years of age $(M=27.55, S D=16.01)$. The offenders ranged from $13-64$ years of age $(M=28.05, S D=9.94)$. The actual age difference between the two was calculated by subtracting the former from the latter, creating continuous data. The difference between a victim's chronological age and an offender's estimated age was also calculated by subtracting the former from the latter, again creating continuous data. For all analyses involving these factors, negative signs associated with values were ignored. The distribution of actual and estimated age differences across cases are in Table 1 (note: this 
table categorises actual and estimated age differences to aid the reader's visualisation of the data. The data was continuous in all analyses).

\section{INSERT TABLE 1 HERE}

Victim race - offender race differences. The number of cases featuring victims and offenders who were White European, Dark European, Afro Caribbean, South Asian, Arabic, Oriental, Mixed Race, or cases where race was unknown are shown in Table 2. All cases where the victim or offender's race was unknown were excluded from analyses involving this factor. For all analyses, the non-excluded cases were categorised according to whether the victim and offender came from the same race (using the categories above) or a different race. In 341 cases $(62.45 \%)$, victims and offenders came from the same race and in 173 cases (31.68\%) they came from different races. In the remaining cases, either the victim or offender's race was unknown. Focusing on the 453 White European victims only, 320 $(70.64 \%)$ were assaulted by someone from the same race, $131(28.92 \%)$ by someone from a different race, and $2(0.44 \%)$ by someone from an unknown race.

\section{INSERT TABLE 2 HERE}

Alcohol consumption levels. In 232 cases (42.50\%), the victims self-reported consuming no alcohol prior to their sexual assault. In 312 cases $(57.14 \%)$, the victims selfreported consuming alcohol. Of these cases, 70 victims self-reported consuming a minimal amount of alcohol, 93 self-reported consuming a moderate amount of alcohol, and 59 selfreported consuming an excessive amount of alcohol. For 90 of the victims who had consumed alcohol, no data was provided regarding the amount consumed. In a further 2 cases $(0.36 \%)$, it was unknown whether victims had consumed alcohol prior to their sexual assault. These latter two types of cases were excluded from all analyses. Whilst it is acknowledged that self-report measures are subjective, no objective data on victims' alcohol consumption levels prior to their assault was available (e.g., Breath Alcohol Content, or BAC, scores). This 
factor was therefore composed of ordinal data, with there being four categories of alcohol consumption (no alcohol, minimal alcohol, moderate alcohol, excessive alcohol).

Duration of exposure. In 499 cases (91.40\%) there was some indication, in minutes, as to how long the victim was exposed to the offender. In some cases, the victims estimated the duration of their assault. In other cases, the victims estimated the time of day when they first interacted with the offender and the time of day when this interaction ended. In these latter cases, the difference between the start and end of the interaction, in minutes, was presumed to be the duration the victim was exposed to the offender. For clarity, these duration of exposure estimations can include time periods that the victim and stranger offender spent together immediately prior to, during, and immediately after an assault. For example, if a victim met a stranger offender in a bar, they spent several hours together in the bar, and the offence took place once they left the bar, then the duration of exposure estimation would include the time spent together in the bar. It is also important to emphasise that victims may not always know the exact start and/or end time of an interaction. Instead, they may offer a non-specific estimate regarding the time of day an interaction started/and or ended. For example, a victim may estimate that an interaction started after 2:00pm and ended before midnight. In such instances, the start of the interaction was coded as 2:01pm and the end of the interaction was coded as 11:59pm. There was also one case in the dataset where an interaction was estimated to begin at 00:01 am and end at 11:59pm. We were unable to establish if this represented a victims' non-specific estimate (e.g., the victim stated the interaction started after midnight/in the early hours of the morning and ended before midnight/late in the evening on the same day) or if only the day on which the interaction occurred was known/recorded and thus the start of the day was coded as the start of the interaction and the end of the day was coded as the end of the interaction. This case was included in the analysis featuring this factor: removing it did not alter the findings. 
This factor was treated as a continuous variable with the data scored in minutes. The durations ranged from 1 minute (the smallest possible time unit in the dataset) to 37830 minutes $(M=282.37, S D=2164.76)$. This upper range limit was inflated by two atypical interactions lasting 30238 and 37830 minutes respectively. IBM SPSS Version 23 identified these two interactions as extreme outliers (i.e., the values were greater than $3 \mathrm{x}$ the interquartile range) so they were removed from all analyses featuring this factor. Their removal produced a new range that spanned from 1 minute to 1438 minutes $(M=147.10, S D$ $=232.01) .53 .33 \%$ of interactions lasted an hour or less.

Seeing a weapon. In 377 cases (69.05\%), no weapon was seen by the victim. These included cases where no weapon was seen or mentioned and cases where the offender claimed to have a weapon but none was seen. In 117 cases $(21.43 \%)$ a weapon was seen. These included cases where the weapon was not displayed but seen, cases where it was displayed but not used, and cases where it was displayed and used. The remaining 52 cases $(9.52 \%)$ had no information regarding whether a weapon was seen and were excluded from all analyses involving this factor. This factor was therefore composed of categorical data and had two conditions (no weapon seen, weapon seen).

Use of sighting precautions. Sighting precautions were used in 72 cases (13.19\%). In the remaining 474 cases $(86.81 \%)$, no sighting precautions were reported. The sighting precautions used included disguises, masks, covering the victim's eyes, asking the victim not to look, and blindfolding the victim. As few of each type were used (e.g., $n=1$ for a mask) it was not possible to examine whether different types of sighting precautions are associated with different degrees of age estimation accuracy. Consequently, for this analysis, these cases were categorised according to whether sighting precautions were used or not.

The passage of time. 509 cases $(93.22 \%)$ included the date on which the sexual assault took place and the date on which it was reported to the police. The difference between 
these two dates, in days, was used as the measure of the time delay between the assault and the age estimation, creating continuous data. In 409 cases $(74.91 \%)$, the sexual assaults were reported on the same day (coded as zero days in the analysis), with the longest time delay being 1510 days $(M=5.83, S D=71.52)$. The upper limit of this range was inflated by four cases with atypical time delays (132, 314, 434, and 1510 days). IBM SPSS Version 23 identified these four cases as extreme values so they were removed from all analyses featuring this factor. Their removal produced a new duration of exposure range spanning from $0-93$ days $(M=1.14, S D=7.78)$.

\section{Data analysis}

All data analysis was conducted using IBM SPSS Version 23. Descriptive statistics were first used to examine absolute age estimation accuracy. t-tests were then used to compare the extent to which exact age estimations and, separately, midpoint age estimations under- and overestimate an offender's true age. A Chi-Squared test was then used to compare the proportion of exact age estimations and midpoint age estimations that were accurate to within 0.99 years, 1 - 2.99 years, 3 - 4.99 years, 5 - 9.99 years of the offenders' age, or 10 or more years from the offender's age.

Next, linear regression analysis was used to examine whether the size of an age range estimation predicts age estimation accuracy. Linear regression was also used to examine whether each of the eight offence-specific factors can predict age estimation accuracy. The victim age - offender age differences factor and victim age - offender estimated age differences factors were analysed separately as they were strongly correlated $(r=.89)$. As the former cannot be used operationally when trying to determine a stranger sexual assault victim's age estimation accuracy (as the offender's age is unknown), the ability of this factor to predict age estimation accuracy was analysed separately in one linear regression. The remaining seven offence-specific factors can potentially be used operationally to determine a 
stranger sexual assault victim's age estimation accuracy, so they were placed into a simultaneous multiple linear regression together. The overall effect of victim race - offender race differences was part of this larger multiple regression. We were also interested in examining whether White European victims' age estimations are subject to an own-race bias when estimating the age of own-race or other-race offenders. As it would be inappropriate to have a large volume of the same data represent two different predictors in a multiple regression, this latter issue was examined in a separate linear regression.

Normal QQ Plots showed that the dependent variable, age estimation accuracy in years, was non-normally distributed. Thus, bootstrapping (with 1000 bootstrap samples) was applied to all statistical tests where the dependent variable was treated as a continuous outcome, using the bootstrapping function in IBM SPSS Version 23, as this approach does not assume a normal distribution (for readers unfamiliar with bootstrapping techniques, see Efron \& Tibshirani, 1994, or Field, 2017, for overviews). For each regression analyses, there was also evidence of homoscedasticity (e.g., see Figure 1), further warranting the use of bootstrapping in these analyses.

\section{Results}

\section{Overall age estimation accuracy}

Victims' absolute mean age estimation error across all cases was 4.78 years $(S D=$ 4.25). In the 120 cases $(21.98 \%)$ where victims provided an exact age estimation, they were inaccurate by an average of 4.02 years $(S D=3.93)$. Of these, 47 underestimated the offender's age by an average of 4.28 years $(S D=3.87)$ and 59 overestimated the offender's age by an average of 4.76 years $(S D=3.91)$. A between-subjects t-test revealed no significant difference in the absolute degree of under- or overestimation by victims who provided an exact age estimation, $t(104)=.64, p=.52, d=.12$. In the 426 cases $(78.02 \%)$ where victims provided an age range estimation (e.g., 20 - 30 years) or a non-exact verbal description (e.g., 
late twenties), their midpoint age estimations were incorrect by an average of 4.99 years ( $S D$ =4.32). 173 of these midpoint age estimations underestimated the offender's age by an average of 5.54 years $(S D=4.67)$ and 243 overestimated the offender's age by 4.81 years $(S D=4.00)$. A between-subjects t-test revealed no significant difference in the absolute degree of under- or overestimation when midpoint age estimations were used as a measure of the offender's true age, $t(414)=1.71, p=.08, d=.17$. Thus, victims were generally more likely to overestimate an offender's age than underestimate it but the degree of under- and overestimation did not significantly differ. Consequently, absolute age estimation error was focused on in all subsequent analyses.

Thomas et al. (2004) previously found only $12 \%$ of rape/attempted rape victims who provided an exact age estimation were accurate to within 1 year of the offender's true age. Here, we divided age estimations up into exact age estimations and midpoint age estimations and found that $11.67 \%$ and $12.68 \%$, respectively, were accurate to within 0.99 years of the offender's true age. Our findings are therefore broadly consistent with those of Thomas et al. When the two age estimation types were combined, estimations in 68 of the 546 cases $(12.45 \%)$ were within 0.99 years of the offender's true age. The total number of age estimations, irrespective of type, within 0.99 years, $1-2.99$ years, $3-4.99$ years, and $5-9.99$ years of the offender's age, or 10+ years from the offender's age, are in Table 3. In an exploratory analysis, a Pearson's Chi-Squared was used to compare the proportion of exact age estimations and midpoint age estimations that fell into each of the above age accuracy categories. It was found that there was no association between the age estimation type and the proportion of estimations that fell into each, $\chi^{2}(4, n=546)=7.49, p=.11$, Cramer's $V=$ .12. This implies that both types of age estimation are broadly equivalent in their accuracy. 
In 232 cases (42.49\%), the victims provided an age range estimation instead of an exact age estimation or a non-specific verbal description. These age range estimations varied in breadth, from 1 year (e.g., 28 - 29 years old) to 20 years (e.g., 30 - 50 years old). The mean breadth of these age range estimations was 4.81 years $(S D=4.48)$ and their mean estimation error, when reduced to midpoints, was 4.55 years $(S D=4.00)$. The next analysis examined whether the breadth of an age range estimation influences its accuracy, as determined by the difference between the midpoint age estimation and the offender's real age. Linear regression demonstrated that the breadth of an age range estimation was a significant predictor of age estimation accuracy, accounting for $13.48 \%$ of its variance, $F(1,230)=35.83, p<.001, R^{2}=$ .13. More specifically as the breadth of an age range estimation increased, age estimation accuracy decreased $($ Constant $=2.94 ; B=.41)$.

\section{Offence-specific factors and age estimation accuracy}

We first examined whether victim age - offender age differences predicted the sexual assault victims' age estimation accuracy when describing the stranger offenders. As expected, they did, $F(1,544)=26.26, p<.001, R^{2}=.05$. Consistent with Thomas et al. (2004), age estimation accuracy decreased as victim age - offender age differences increased (see Figure 1 for a visual depiction and the information needed for a regression equation). The victims therefore had an own-age bias when estimating offenders' ages.

\section{INSERT FIGURE 1 HERE}

Next, the remaining seven offence-specific factors were included in a simultaneous multiple regression to see if they also predicted the sexual assault victims' age estimation accuracy. The overall model did predict age estimation accuracy, $F(9,436)=2.22, p=.02$, $R^{2}=.04$. Amongst the individual factors, however, only victim age - offender estimated age differences significantly predicted the outcome. Consistent with Thomas et al. (2004), there was an own-age bias evident, with age estimation accuracy decreasing as victim age - 
offender estimated differences increased (see Figure 1). For brevity, the statistical output for each factor within the multiple regression is presented in Table 4.

Whilst overall victim race - offender race differences did not predict age estimation accuracy in the multiple regression (see Table 4), it was possible that our White European victims only, who featured in most cases, would have an own-race bias when producing age estimations (as in Dehon \& Brédart, 2001). We therefore tested for this. Whilst there was a trend towards White European victims in same-race cases producing more accurate age estimations (Constant $=4.55 ; B=.75)$, the effect was not statistically significant, $F(1,451)=$ $3.09, p=.08, R^{2}=.01$.

\section{INSERT TABLE 4 HERE}

\section{Discussion}

This archival analysis examined stranger sexual assault victims' age estimation accuracy when describing stranger offenders and tested whether eight offence-specific factors can predict their accuracy.

\section{Overall age estimation accuracy}

In the first ever examination of this issue, we found the victims' mean absolute age estimation error was 4.78 years. This means the victims were slightly more accurate than participants in many laboratory-based age estimation studies (see Moyse, 2014) but slightly less accurate than robbery victims (Tollestrup et al., 1994). Just over one-fifth of sexual assault victims provided an exact age estimation, with $11.67 \%$ being within 0.99 years of the offenders true age. Thomas et al. (2004) found an almost identical figure in their study of rape/attempted rape victims' age estimations. The remaining victims in our analysis provided an age range estimation or a non-exact verbal description and the midpoint was used as the estimation (reflecting practices during real police investigations). The accuracy of these midpoint age estimations had never previously been examined. $12.68 \%$ were within 0.99 
years of the offenders true age, mirroring the exact age estimations. Additionally, the degree of under/overestimation observed was comparable for both types of age estimation.

Combined, our findings suggest exact and midpoint age estimations are broadly equivalent in their accuracy but that precise age estimations, regardless of type, are rare.

It was also found that just over two-fifths of sexual assault victims provided an age range estimation only, with the range spanning 1 - 20 years. It was previously unknown whether the span of an age range estimation, when reduced to a midpoint, can predict its accuracy. Here we found it can, with broader age range estimations being least accurate.

\section{Offence-specific factors and age estimation accuracy}

Only two of the eight offence-specific factors predicted victims' age estimation accuracy (when exact and midpoint age estimations were pooled). The first was victim age offender age differences, with smaller differences resulting in greater accuracy. This replicates Thomas et al.'s (2004) earlier finding with a new larger sample, suggesting a reliable own-age bias effect occurs when sexual assault victims estimate a stranger offender's age. This effect has also been observed in laboratory-based studies where participants make age estimations whilst (or shortly after) looking at photographs of strangers (e.g., Anastasi \&

Rhodes, 2006; Moyse \& Brédart, 2012; George \& Hole, 1995; George et al., 2000; Voelkle et al., 2012). Our finding therefore has external validity. The leading explanation for this effect is the perceptual-expertise hypothesis, which suggests individuals have most day-to-day contact with members of their own age group and become experts at estimating the age of own, relative to other, age faces (see Moyse \& Brédart, 2012). It is possible a similar mechanism underpins the own-age bias effect observed here.

The second offence-specific factor to predict the sexual assault victims' age estimation accuracy was victim age - offender estimated age differences, with another ownage bias effect observed. This also replicates one of Thomas et al.'s (2004) findings. 
Knowing that an own-age bias effect reliably occurs when sexual assault victims estimate a stranger offender's age is important as it helps police investigators understand the conditions under which age estimations may be more or less accurate.

Exploratory analysis also revealed that victim race - offender race differences, when several different racial groups featured in the analysis, did not predict age estimation accuracy. Previously, a laboratory study by Dehon and Brédart (2001) found that White participants (in a White majority country) were better at estimating the ages of White faces than Black faces. They speculated that this own-race bias effect occurred as their White participants had more daily contact with White people than Black people, meaning they developed perceptual-expertise in estimating the age of own-race faces. As most of our victims were White Europeans, and they were in a White majority country, we also examined whether their age estimation accuracy was subject to an own-race bias. Whilst there was a trend towards such an effect, it was not significant. It is impossible to know why we did not replicate Dehon and Brédart's findings but our data did have a general trend that was consistent with theirs. The two sets of findings could differ as the amount of contact our victims/their participants had with people from their own and other races differed (neither study measured this). Alternatively, the two set of findings could differ as the conditions under which our sexual assault victims and their laboratory-based participants made age estimations is very different. Further research is needed to resolve this conundrum.

Here, just over half of the victims self-reported consuming alcohol prior to their assault, which is a typical observation (Abbey et al., 2004; Littleton \& Breitkopf, 2006; Orchowski et al., 2013). Previously, Thomas et al. (2004) found that rape/attempted rape victims' age estimation accuracy was unaffected by alcohol consumption. They did not, however, consider whether the volume of alcohol consumed influenced accuracy. Our analysis revealed the self-reported volume of alcohol consumed, even when excessive, did 
not predict victims' age estimation accuracy. We acknowledge, however, that self-reported alcohol consumption levels are subjective so this could affect the validity of our findings. Interestingly, however, memory of faces (which provide cues about a person's age) is often unaffected by alcohol consumption and it is possible this more general effect extends to age estimation (see Altman et al., In Press).

Our analysis also revealed the amount of time victims spent with offenders, despite ranging from 1 to 1438 minutes, did not predict their age estimation accuracy. Previously, Thomas et al. (2004) found that victims who had spent less than one hour with an offender and those who had spent more than one hour with an offender were equivalent in their accuracy. Our re-examination of this issue, when duration of exposure was treated as a continuous variable, suggests this null effect is reliable. We acknowledge, however, that the shortest duration of exposure unit in both studies was 1 minute. Archival research on eyewitnesses' age estimations, when describing stranger offenders, suggests shorter durations may reduce age estimation accuracy (Granhag et al., 2013). Future research should consider whether this also occurs when sexual assault victims are exposed to stranger offenders for shorter durations. It would also be helpful if duration of exposure could be measured more objectively (e.g., via CCTV footage) as people often overestimate the duration of stressful events (Loftus, Schooler, Boone, \& Kline, 1987).

Whilst one-fifth of the offenders in our analysis had a weapon that was seen by their victims during the sexual assault, seeing a weapon, relative to not seeing one, did not predict victims' age estimation accuracy. This also replicates an earlier finding by Thomas et al. (2004). In the eyewitness memory literature, both archival and laboratory-based studies have shown the presence of a weapon during a crime has little or no effect on suspect identification 
in lineups (see Valentine, Pickering, \& Darling 2003; Kocab \& Sporer, 2016, respectively) 3 . Thus, once again, it is possible that this more general finding, which centres on what people look like, extends to age estimation.

We also found $13.19 \%$ of offenders employed sighting precautions but that the use of sighting precautions did not predict victims' age estimation accuracy. This also replicates an earlier finding by Thomas et al. (2004). The relatively small proportion of sighting precautions in this analysis, however, warrants consideration as it could reduce the validity of these findings. Additionally, we were also unable to examine whether different types of sighting precautions have a unique influence on victims' age estimation accuracy due to the small numbers of each type used. Examining this in future would be beneficial as some sighting precautions may be more effective than others at preventing accurate age estimations (e.g., it may be harder to estimate the age of an offender whose entire face is covered by a mask than it is to estimate the age of an offender whose face is partially covered by a scarf).

Finally, our analysis also found that the passage of time between an assault taking place and a victim describing a stranger offender to the police, despite ranging from 0 to 93 days, did not predict age estimation accuracy. This finding is consistent with that of other age estimation studies (e.g., Ebbesen \& Rienick, 1998; Yuille \& Cutshall, 1986).

\section{Limitations}

All archival analyses that focus on victims' or eyewitnesses' descriptions of offenders must be treated with caution. Archival analyses of this nature utilise data taken from police records and this data may be flawed due to unreliable documentation procedures (see Davies, 1992; Farrington \& Lambert, 1997; Sporer, 1996). In Thomas et al.'s (2004) earlier analysis, however, they were able to compare a sample of the victim statements to the coding in their

\footnotetext{
${ }^{3}$ Laboratory-based studies have shown participants' verbal description of an offender can be impaired if the offender is armed (see Kocab \& Sporer's, 2016, meta-analysis).
} 
dataset and found few errors. As we did not have access to the original victim statements, a similar quality check could not be made. It is, however, reassuring to know that few errors were detected in their earlier work as our dataset derived from the same source.

An additional problem with archival data is that researchers are restricted in the number of issues that can be explored. It is likely that the victims' age estimation accuracy was influenced by other offence-specific factors that could not be accounted for here. The fact that the offence-specific factors in this study only accounted for a small proportion of the variance in age estimation accuracy supports this claim. Although it is beyond the scope of this analysis to speculate about other potential factors, it is important to acknowledge that we only focused on those that could have influenced victims' age estimation accuracy prior to them making a police statement. The interview techniques used by police investigators during the victim interviews may have also influenced age estimation accuracy. For example, it is known that enhanced interview techniques, such as the Cognitive Interview, produce more accurate descriptions of offenders than standard techniques (Fisher \& Geiselman, 1992; Köhnken, Milne, Memon, \& Bull, 1999). Unfortunately, it was impossible to examine the impact of different interview techniques on age estimation accuracy here.

The restrictive nature of archival studies can also reduce the generalisability of findings. The present study focused solely on offences with male offenders/female victims. Although rarer, stranger sexual assaults can occur with other gender combinations (e.g., male victims/female offenders). Gender differences have been observed in laboratory-based age estimation studies, with females producing more accurate estimations than males (Vestlund, Langeborg, Sorqvist \& Eriksson, 2009). These differences may also be observed when male and female sexual assault victims estimate the age of stranger offenders. Research is needed to establish this. Furthermore, in order to confirm the accuracy of victims' age estimations, only solved cases in which the offender had been convicted were analysed. This presents a 
biased representation of sexual assault cases, as many go unreported and those that are reported often fail to produce a conviction (Kelly, Lovett \& Regan, 2005; Crown Prosecution Service, 2016). Consequently, it is impossible to know whether victims of unreported or unsolved stranger sexual assaults would produce more or less accurate age estimations or whether these cases are associated with common offence-specific factors (e.g., large victim age - offender estimated age differences). Unfortunately, we were unable to examine these issues as we could not access any data relating to unsolved sexual assaults.

\section{Conclusion}

This study provides the first overview (in an academic publication) of sexual assault victims' age estimation accuracy when describing stranger offenders and the offence-specific factors that influence their accuracy. Only one in five victims provided an exact age estimation, with the majority providing an age range estimation/non-specific age description from which a midpoint age estimation could be derived. Exact and midpoint age estimations were broadly equivalent in their accuracy, with their mean age estimation error being 4.78 years, just over one in ten age estimations being within 0.99 years of an offender's age, and nearly nine in ten age estimations being within 9.99 years of an offender's age. If victims provided age range estimations and the midpoints of these were used as exact age estimations, then those victims that produced narrower age range estimations were most accurate. Age estimations were also most accurate when victim age - offender age differences and victim age - offender estimated age differences were small. These findings can help investigators, and the specialists who support them, to understand sexual assault victims' likely age estimation accuracy when describing stranger offenders. 


\section{References}

Abbey, A., Zawacki, M. A., Buck, P. O., Clinton, A. M., \& McAuslan, P. (2001). Alcohol and sexual assault. Alcohol Research and Health, 25, 43-51.

Altman, C. M., Schreiber Compo, N., McQuiston, D., Hagsand, A. V., \& Cervera, J. (In Press). Witnesses' memory for events and faces under elevated levels of intoxication. Memory. doi:10.1080/09658211.2018.1445758

Anastasi, J. S., \& Rhodes, M. G. (2006). Evidence for an own-age bias in face recognition. North American Journal of Psychology, 8, 237-252.

Clifford, B. R., Havard, C., Memon, A., \& Gabbert, F. (2012). Delay and age effects on identification accuracy and confidence: An investigation using a video identification parade. Applied Cognitive Psychology, 26, 130-139. doi:10.1002/acp.1804

Crown Prosecution Service. (2016). Violence against Women and Girls. Retrieved August, 2017, from: http://www.cps.gov.uk/publications/docs/cps_vawg_report_2016.pdf

Davies, G. M. (1992). Influencing public policy on eyewitnessing: Problems and possibilities. In F. Losel, D. Bender, \& T. Bliesener (Eds.), Psychology and law: International perspectives (pp. 265-274). Berlin: De Gryuyter.

Dehon, H., \& Brédart, S. (2001). An “other-race" effect in age estimation from faces. Perception, 30, 1107-1113. doi:10.1068/p3122

Ebbesen, E. B., \& Rienick, C. B. (1998). Retention interval and eyewitness memory for events and personal identifying attributes. Journal of Applied Psychology, 83, 745762. doi:10.1037/0021-9010.83.5.745

Efron, B., \& Tibshirani, R. J. (1994). An Introduction to the Bootstrap. Boca Raton: CRC Press.

Fahsing, I. A., Ask, K., \& Granhag, P. A. (2004). The man behind the mask: Accuracy 
and predictors of eyewitness offender descriptions. Journal of Applied Psychology, 89, 722-729. doi:10.1037/0021-9010.89.4.722

Farrington, D. P., \& Lambert, S. (1997). Predicting offender profiles from victim and witness descriptions. In J. L. Jackson \& D. A. Bekerian (Eds.), Offender profiling: Theory, research, and practice (pp. 133-158). Chichester, England: Wiley.

Feist, A., Ashe, J., Lawrence, J., McPhee, D., \& Wilson, R. (2007). Investigating and detecting recorded offences of rape. Home Office Online Report 18/07. London, United Kingdom: Home Office.

Field, A. (2017). Discovering statistics using SPSS (5th ed.). London: Sage.

Fisher, R. P., \& Geiselman, R. E. (1992). Memory-enhancing techniques for investigative interviewing: The Cognitive Interview. Springfield, IL: Charles C Thomas.

George, P.A., \& Hole, G.J. (1995). Factors influencing the accuracy of age estimations of unfamiliar faces. Perception, 24, 1059-1073. doi:10.1068/p241059

George, P.A., Hole, G.J., \& Scaife, M. (2000). Factors influencing young children's ability to discriminate unfamiliar faces by age. International Journal of Behavioral Development, 24, 480-491. doi:10.1080/016502500750038035

Granhag, P. A., Ask, K., Rebelius, A., Öhman, L., \& Mac Giolla, E. (2013). 'I saw the man who killed Anna Lindh!' An archival study of witnesses' offender descriptions. Psychology, Crime, \& Law, 19, 921-931. doi:10.1080/1068316X.2012.719620

Harrison, V., \& Hole, G. J. (2009). Evidence for a contact-based explanation of the ownage bias in face recognition. Psychonomic Bulletin \& Review, 16, 264-269. doi: 10.3758/PBR.16.2.264

Kelly, L., Lovett, J. \& Regan, L. (2005). A gap or a chasm? Attrition in reported rape cases. Home Office Research Study 293. London, United Kingdom: Home Office.

Kocab, K., \& Sporer, S. L. (2016). The Weapon Focus Effect for Person Identifications and 
Descriptions: A Meta-analysis. In B. H. Bornstein, \& M. K. Miller (Eds), Advances in psychology and law (pp. 71-117). Springer International Publishing.

Köhnken, G., Milne, R., Memon, A., \& Bull, R. (1999). The cognitive interview: A metaanalysis. Psychology, Crime \& Law, 5, 3-28. doi:10.1080/10683169908414991

Littleton, H. L., \& Breitkopf, C. (2006). Coping with the experience of rape. Psychology of Women Quarterly, 30, 106-116. doi:10.1111/j.1471-6402-2006.00267.x

Loftus, E. F., Schooler, J. W., Boone, S. M., \& Kline, D. (1987). Time went by so slowly: Overestimation of event duration by males and females. Applied Cognitive Psychology, 1, 3-13. doi:10.1002/acp.2350010103

Moyse, E. (2014). Age estimation from faces and voices: a review. Psychologica Belgica, 54, 255-265. doi:10.5334/pb.aq

Moyse, E., \& Brédart, S. (2012). An own-age bias in age estimation of faces. Revue Européenne de Psychologie Appliquée/European Review of Applied Psychology, 62, 3-7. doi:10.1016/j.erap.2011.12.002

Office for National Statistics. (2013). An overview for sexual offending in England and Wales. London, United Kingdom: Home Office. Retrieved August, 2017, from: https://www.gov.uk/government/statistics/an-overview-of-sexual-offending-in$\underline{\text { england-and-wales }}$

Orchowski, L., Untied, A., \& Gidycz (2013). Social reactions to disclosure of sexual assault and adjustment among survivors of sexual assault. Journal of Interpersonal Violence, 28, 2005-2023. doi:10.1177/0886260512471085.

Read, J., Yuille, J., \& Tollestrup, P. (1992). Recollections of a robbery. Law and Human Behavior, 16, 425-446. doi:10.1007/BF02352268

Rhodes, M. G. (2009). Age estimation of faces: A review. Applied Cognitive Psychology, 23, 1-12. doi:10.1002/acp.1442

Sporer, S. L. (1996). Describing others: Psychological issues. In S. L. Sporer, R. S. Malpass, 
\& G. Koehnken (Eds.), Psychological issues in eyewitness identification (pp. 53-86). Hillsdale, NJ: Lawrence Erlbaum.

Thomas, N., Aitken, C., Lucy, D. \& Feist, A. (2004). Predicting the Accuracy of Stranger Rape Victims Statements. Special Interest Series Paper No 15. London, United Kingdom: Home Office.

Thorley, C., \& Christiansen, P. (2018). The impact of own and others' alcohol consumption on social contagion following a collaborative memory task. Memory, 26, 727-740. doi:10.1080/09658211.2017.1404110

Tollestrup, P. A., Turtle, J. W., \& Yuille, J. C. (1994). Actual victims and witnesses to robbery and fraud: An archival analysis. In D. F. Ross, J. D. Read, \& M. P. Toglia (Eds.), Adult eyewitness testimony: Current trends and developments (pp. 144-162). New York: Cambridge University Press.

Valentine, T., Pickering, A. and Darling, S. (2003). Characteristics of eyewitness identification that predict the outcome of real lineups. Applied Cognitive Psychology, 17, 969-993. doi:10.1002/acp.939

van Koppen, P. J., \& Lochun, S. K. (1997). Portraying perpetrators: The validity of offender descriptions by witnesses. Law and Human Behavior, 21, 661-685. doi:10.1023/A:1024812831576

Van Oorsouw, K., \& Merckelbach, H. (2012). The effects of alcohol on crime-related memories: A field study. Applied Cognitive Psychology, 26, 82-90. doi:10.1002/acp.1799

Van Oorsouw, K., \& Merkelbach, H., \& Smeets, T. (2015). Alcohol intoxication impairs memory and suggestibility for a mock crime: A field study. Applied Cognitive Psychology, 29, 493-501. doi:10.1002/acp.3129

Vestlund, J., Langeborg, L., Sorqvist, P., \& Eriksson, M. (2009). Experts on age estimation. Scandinavian Journal of Psychology, 50, 301-307. doi:10.1111/j.14679450.2009.00726.x 
Voelkle, M. C., Ebner, N. C., Lindenberger, U., \& Riediger, M. (2012). Let me guess how old you are: Effects of age, gender, and facial expression on perceptions of age. Psychology \& Aging, 27, 265-277. doi:10.1037/a0025065

Yuille, J. C. \& Cutshall, J. L. (1986). A case study of eyewitness memory of a crime. Journal of Applied Psychology, 71, 291-301. doi:10.1037/0021-9010.71.2.291 
Table 1: The number of cases where the victim age - offender age differences (calculated using either the offender's chronological age or the offender's estimated age) differed by 0 0.99 years, 1 - 2.99 years, 3 - 4.99 years, 5 - 9.99 years, 10 - 14.99 years, $15-19.99$ years, and 20+ years. The percentage of cases for each type of victim age - offender age difference are in parentheses.

\begin{tabular}{lcc}
\hline Age Difference & Victim Age - Offender & Victim Age - Offender \\
& Age Difference & Estimated Age Difference \\
\hline 0 - 0.99 years & $17(3.11 \%)$ & $28(5.13 \%)$ \\
$1-2.99$ years & $76(13.92 \%)$ & $72(13.19 \%)$ \\
$3-4.99$ years & $72(13.19 \%)$ & $87(15.93 \%)$ \\
$5-9.99$ years & $128(23.44 \%)$ & $125(22.90 \%)$ \\
$10-14.99$ years & $81(14.83 \%)$ & $81(14.83 \%)$ \\
$15-19.99$ years & $53(9.71 \%)$ & $60(10.99 \%)$ \\
$20+$ years & $119(21.80 \%)$ & $93(17.03 \%)$ \\
\hline Total & $546(100 \%)$ & $546(100 \%)$ \\
\hline
\end{tabular}


Table 2: The number of cases featuring victims and offenders who were White European, Dark European, Afro Caribbean, South Asian, Arabic, Oriental, Mixed Race, or cases where race was unknown. The percentage of cases are in parentheses.

\begin{tabular}{lcc}
\hline Racial Classification & Victim & Offender \\
\hline White European & $453(82.97 \%)$ & $363(66.48 \%)$ \\
Dark European & $32(5.86 \%)$ & $85(15.57 \%)$ \\
Afro Caribbean & $8(1.46 \%)$ & $54(9.89 \%)$ \\
South Asian & $5(0.92 \%)$ & $3(0.55 \%)$ \\
Arabic & $0(0.00 \%)$ & $20(3.66)$ \\
Oriental & $9(1.65 \%)$ & $18(3.30 \%)$ \\
Mixed Race & $9(1.65 \%)$ & $1(0.18 \%)$ \\
Unknown & $30(5.49 \%)$ & $2(0.37 \%)$ \\
\hline Total & $546(100 \%)$ & $546(100 \%)$ \\
\hline
\end{tabular}


Table 3: Number of cases where sexual assault victims' age estimations (separated into exact age estimations and midpoint age estimations) were accurate to within 0.99, 1 - 2.99, 3 4.99, and 5 - 9.99 years of the offender's age or more than 10 years from the offender's age. The percentage of all cases for each age estimation type are in parentheses.

\begin{tabular}{lccc}
\hline Accuracy Level & Exact Age & Midpoint Age & Total \\
& Estimations & Estimations & \\
\hline $0-0.99$ years & $14(11.67 \%)$ & $54(12.68 \%)$ & $68(12.45 \%)$ \\
$1-2.99$ years & $46(38.33 \%)$ & $113(26.53 \%)$ & $159(29.12 \%)$ \\
$3-4.99$ years & $21(17.50 \%)$ & $87(20.42 \%)$ & $108(19.78 \%)$ \\
$5-9.99$ years & $23(19.17 \%)$ & $117(27.46 \%)$ & $140(25.64 \%)$ \\
$10+$ years & $16(13.33 \%)$ & $55(12.91 \%)$ & $71(13.00 \%)$ \\
\hline Total & $120(100 \%)$ & $426(100 \%)$ & $546(100 \% *)$ \\
\hline
\end{tabular}

Note: The values in the Total column do not sum to $100 \%$ due to rounding error 
Table 4: Multiple regression individual predictor output, after bootstrapping with 1000 samples, examining whether seven offence-specific factors predict sexual assault victims' age estimation accuracy when describing stranger offenders

\begin{tabular}{|c|c|c|c|c|}
\hline \multicolumn{5}{|c|}{ Unstandardised Coefficients } \\
\hline & $\underline{B}$ & $\underline{\text { Std. Error }}$ & $\underline{\text { Bias }}$ & Sig. \\
\hline Constant & 3.74 & 0.43 & .02 & .001 \\
\hline $\begin{array}{l}\text { Victim Age - Offender } \\
\text { Estimated Age Difference }\end{array}$ & 0.06 & 0.02 & -.01 & .007 \\
\hline Race Differences & 0.58 & 0.35 & -.01 & .09 \\
\hline Time Delay & 0.01 & 0.03 & -.01 & .80 \\
\hline Duration of Exposure & 0.01 & 0.01 & .01 & .66 \\
\hline Weapon Seen & -0.45 & 0.47 & -.01 & .92 \\
\hline Minimal Alcohol & 0.19 & 0.67 & .04 & .77 \\
\hline Moderate Alcohol & -0.13 & 0.51 & .01 & .79 \\
\hline Excessive Alcohol & -0.89 & 0.57 & .01 & .13 \\
\hline Sighting Precautions & 1.00 & 0.73 & -.04 & .17 \\
\hline
\end{tabular}

Note: The following categorical factors (written outside of parentheses) had the following reference categories (written inside of parentheses): Race Differences (Same Race), Weapon Seen (No Weapon Seen), Alcohol Consumption (No Alcohol), Sighting Precautions (No Sighting Precautions 


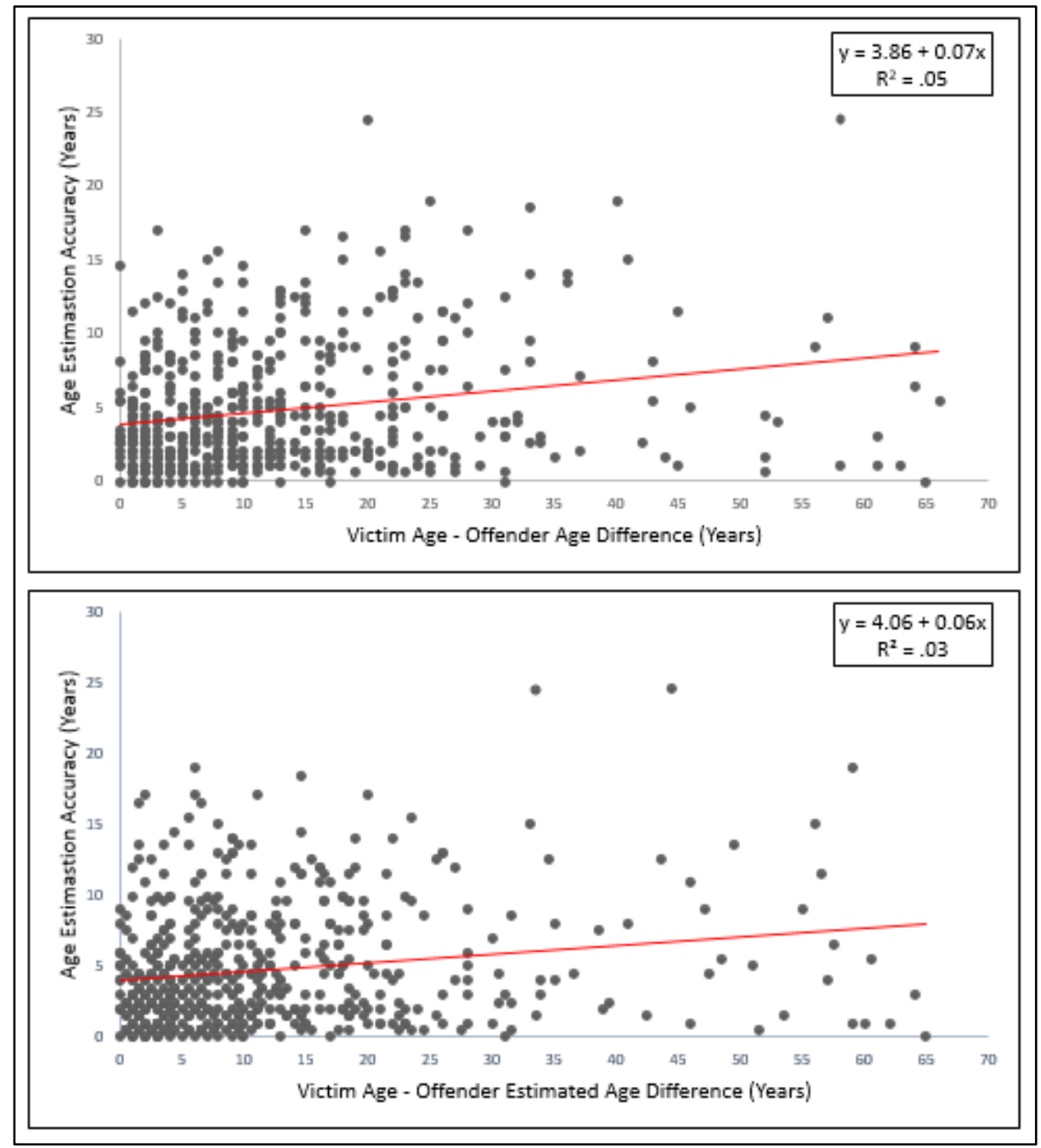

Figure 1: Sexual assault victims' age estimation accuracy, plotted against victim age offender age differences (top figure) and victim age - offender estimated age differences (bottom figure). Each figure includes its regression equation and the associated $R^{2}$ value. 